\title{
MATERIALS FOR AUTOMOTIVE INDUSTRY AND THEIR INFLUENCE ON THE DYNAMICS OF A CAR CRASH
}

\author{
NAVODARIU NICOLAE ${ }^{* 1}$, CIOCOIU ROBERT ${ }^{1}$, TRANTE OCTAVIAN ${ }^{1}$, \\ ANTONIAC VASILE IULIAN ${ }^{1}$
}

\author{
University Politehnica of Bucharest, Faculty of Material Science and Engineering, Splaiul \\ Independentei $n r .313$, Bucharest, Romania
}

\begin{abstract}
The aim of this research was to determine the influence of the metallic materials characteristics on the dynamics of a car crash. Another important aspect is that the metallic parts are sometimes repaired after minor accidents and this fact influence strongly the mechanical characteristics and their influence on the dynamics of a car crash. In this paper, we analyze the mechanical characteristics of thin steel plates repaired by local heating associated with plastic deformation (similar to hot working) and cold straightening (similar to local cold working) for automotive side and door panels made of structural steel. Thin sheet plates, $0.9 \mathrm{~mm}$ thickness, were deformed by impact and repaired by local heating using the flame and induction heating then plastically deformed while hot as well as straightened without heating. The heat repaired samples were studied by light microscopy to determine microstructure change and samples were tensile tested to determine their mechanical characteristics. Local excessive grain growth generates anisotropy, the assembly behaves as a composite material with regions that show significant plastic deformations while others little or no deformations at all. Without procedures adjusted to each material repairs involving heating are to be avoided, cold working should be employed when replacement is not possible.
\end{abstract}

Keywords: automotive, car crash, repairs

\section{INTRODUCTION}

The unitary body structure of a car is comprised of three compartments [1]:

- the extended front compartment, extending over and ahead of the front wheels;

- the middle compartment, delimited by the front and rear wheel axels;

- the behind compartment, extending behind the back axle.

These compartments are constructed as a framework loaded in tension or compression with components made from rolled sheet steel pressed in rectangular, triangular, trapezoidal or a combination of these shapes [1].

Car safety can be regarded as active safety, concerned with car's road holding stability while drive, steered or braked and passive safety, dependent upon design of the structure to protect the passengers in case of collision [2]. In respect to passive safety, the car can be divided in two regions $[1,2]$ :

- a crushproof cell, corresponding to the middle compartment, with a rigid platform and the chassis which creates a rigid and reinforced construction;

\footnotetext{
* Corresponding author, email: nicolae.navodariu@ volvo.com

(C) 2019 Alma Mater Publishing House
} 
- the crumble zone which comprises both the extended front and behind compartment, designed to form zones that collapse and crumble progressively over the duration of the impact.

The most of kinetic energy will be absorbed in the crumble zone by strain and plastic deformation and little would be transferred to the crushproof cell $[1,2]$.

Given this modes of kinetic energy absorption materials play an important role in this picture. Steels are still widely used by most car manufacturers and their behavior and a study was performed regarding the deformations in tension $[3,4]$.

Work hardening or strain hardening means metal strengthening by plastic deformation and this method is applied for alloys not amenable to heat treatment.

This phenomenon is described, mathematically, by Hollomon's equation (1) [4, 5]:

$$
\sigma=K \epsilon_{p}^{n}
$$

Hollomon's equation is a power law where $\sigma$ is the stress, $K$ is the stress index, $\varepsilon$ is the plastic strain and $\mathrm{n}$ is the strain hardening exponent $[4,5]$.

Equation (1) does not comply to our needs since it does not accounts for yielding therefore Ludwik's equation (2) was used [4 - 6].

$$
\sigma=\sigma_{0}+K \varepsilon^{n}
$$

Equation (2) is similar, but it includes the yield stress $\sigma_{0}$ which should provide more accurate results for this study.

Both equations were applied on tensile test results performed on test samples obtained from side panels and the stress index $\mathrm{K}$ and the strain hardening exponent $\mathrm{n}$ were determined for steels in various structural states.

\section{MATERIALS AND METHODS}

For this study side panels were used which were slightly deformed by impact to simulate a mild crash and the repaired using two methods: warm straightening and cold working (by hammering). Warm straightening was performed using an oxyacetylene torch and by induction.

Tensile test specimens according to ISO 6892-1/2016 were obtained from these panels, 5 per each panel. The specimens obtained are symbolized in Table 1.

Table 1. Specimen coding and corresponding processing.

\begin{tabular}{|c|c|}
\hline Specimen code & Processing \\
\hline R & Reference, no deformation/no processing performed \\
\hline F & Deformed and straightened using local heating by oxyacetylene torch \\
\hline I & Deformed and straightened using local heating by induction \\
\hline H & Deformed and straightened by cold working (hammering) \\
\hline
\end{tabular}

For tensile tests a Walter+Bai LFV300 servohydraullic universal testing machine was used, testing parameters were set according to ISO 6892-1/2016.

Specimens were also obtained and prepared for metallographic investigations using the ReichertUnivar light microscope with corresponding image acquisition software.

The chemical composition of the steel was determined by optical emission spectrometry using a SPECTROMAXX spectrometer. 


\section{RESULTS AND DISCUSSION}

\subsection{Chemical composition of the alloy}

On each panel used for this study chemical composition was determined using the SPECTROMAXX optical emission spectrometer. In Table 2 a mediated chemical composition is presented, all panels were made of same type of alloy.

Table 2. Chemical composition of the steel.

\begin{tabular}{|l|l|l|l|l|l|l|l|l|l|}
\hline Element & $\% \mathrm{C}$ & $\% \mathrm{Si}$ & $\% \mathrm{Mn}$ & $\% \mathrm{Cr}$ & $\% \mathrm{Ni}$ & $\% \mathrm{Cu}$ & $\% \mathrm{P}$ & $\% \mathrm{~S}$ & $\% \mathrm{Fe}$ \\
\hline$\% \mathrm{wt}$ & 0.051 & 0.059 & 0.110 & 0.023 & 0.021 & 0.015 & 0.013 & 0.0092 & Bal. \\
\hline
\end{tabular}

The chemical composition shows that the alloy is a structural non alloyed mild steel complying with Werkstoffnummer 1.0335 requirements for chemical composition.

\subsection{Light microscopy studies}

The samples used for light microscopy studies were prepared using the specific protocol for steel [7] and the observed using the ReichertUnivar light microscope.

The microstructure presented in Figure 1 at different magnifications revealed a microstructure composed mainly of a solid solution, ferrite, with fine grains and a slight preferred orientation given by the processing method. According to the iron - cementite phase diagram this hypo-eutectoid steel should have a microstructure comprised of a mixture of ferrite and pearlite, but given the small amounts of the later it was difficult to detect it by light microscopy.
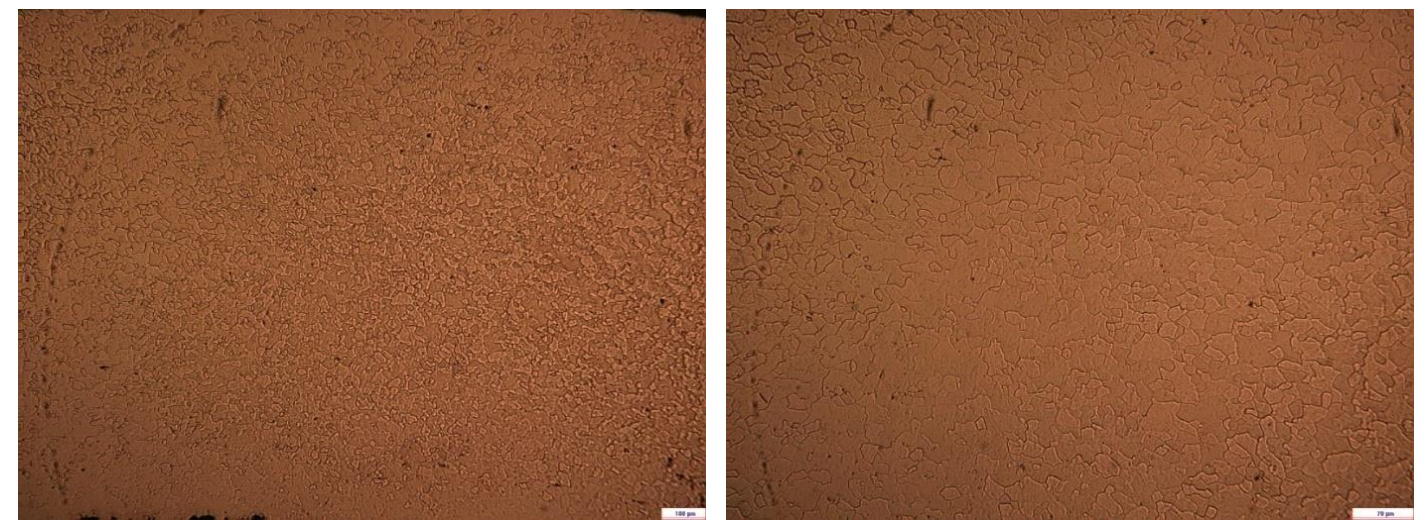

Fig. 1. Optical micrographs on the reference specimens showing a ferritic microstructure with a slight texture.

\subsection{Tensile testing}

Tensile specimens with dimensions according to ISO 6892-1/2016 were obtained from the experimental panels, 5 test samples/panel and tested using the universal testing machine Walter+Bai LFV 300. Test parameters were set to comply with ISO 6892-1/2016 specifications.

The selection of stress - strain curves shown in Figure 2 depicts the tensile behavior of the specimens in relation to their processing. The reference specimens, R, show a typical behavior of a work hardened mild steel, with an appreciable ductility and no apparent yield point. In a similar manner, the cold worked samples, H, do not show an apparent yield point.

The tensile specimens obtained from the repaired panels which involved heating alter their behavior: an apparent yield point appears, specific for mild steels in an annealed state. It can be stated that by local heating and given the low thickness of the specimens, $0.9 \mathrm{~mm}$, an annealing heat treatment like process was performed, removing previous cold working effects. 


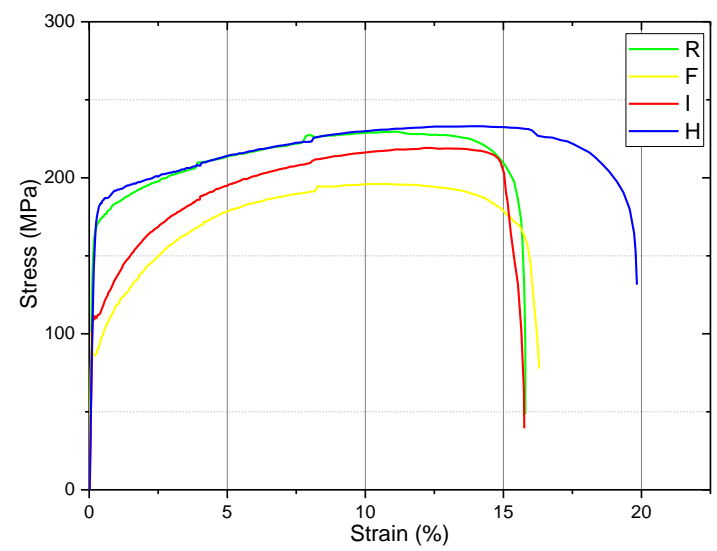

Fig. 2. Stress - strain curves showing a representative selection for the tensile behavior.

The experimental results are presented in Figure 3 as bar charts depicting the average value with the associated confidence interval estimated at $\alpha=0.05$.

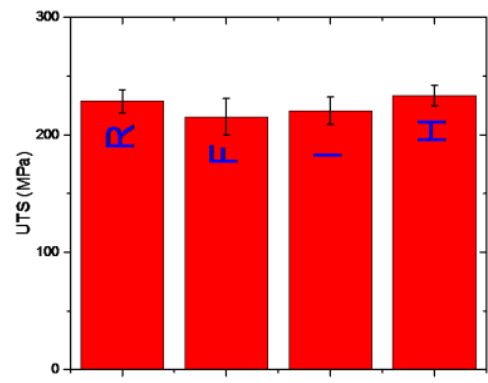

a.

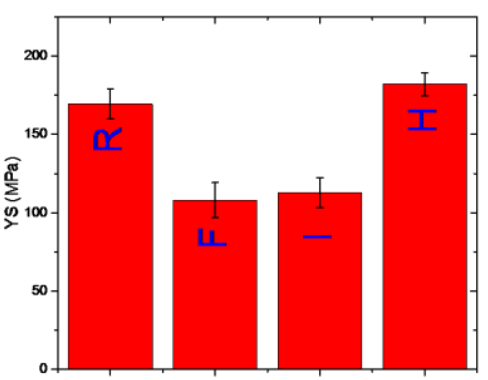

b.

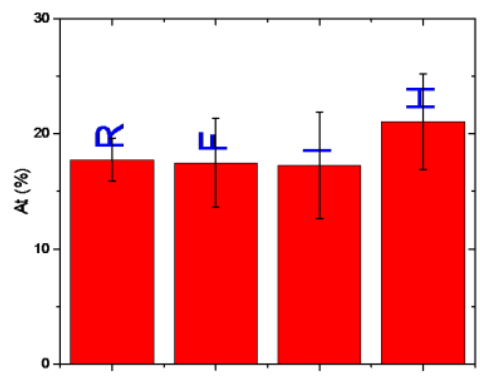

c.

Fig. 3. Experimental results comparison of a. ultimate tensile strength (UTS), b. yield strength (YS) and c. total elongation after failure (At).

In Figure 3.a. the ultimate tensile strength (UTS) variation is presented. Its values do not vary as strongly as expected, but the spread of the values given by the standard deviation of the heated samples is significantly larger on the flame heated samples - a process performed by hand, using a torch.

The yield strength (YS) varies, as depicted in Figure 3.b., in a typical manner: the locally cold worked samples H show the highest values, followed close by the reference samples R and lowest values were found in the samples repaired using heating by flame $\mathrm{F}$ and induction $\mathrm{I}$.

The total elongation after failure (At) varies in an unusual manner, as seen in Figure 3.c. It would be expected that the cold worked samples would show lowest values and highest values should be observed in heated specimens. Given the repairing process the samples suffer local microstructure changes and become inhomogeneous and perhaps isotropic [3].

When this type of specimens are to be mechanically tested the yield strength is the best descriptor for the mechanical properties.

\subsubsection{A study on the tensile behavior using the strain hardening exponents}

Using the experimental stress - strain curves the stress index $K$ and the strain hardening exponent $\mathrm{n}$ were determined using Hollomon's and Ludwik's equations [8].

The results obtained using Hollomon's equation are shown as bar hart comparison in Figure 4. 


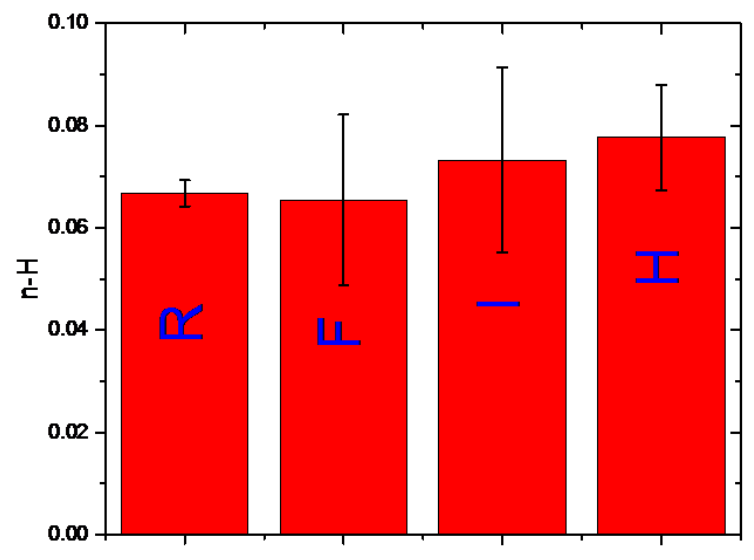

a.

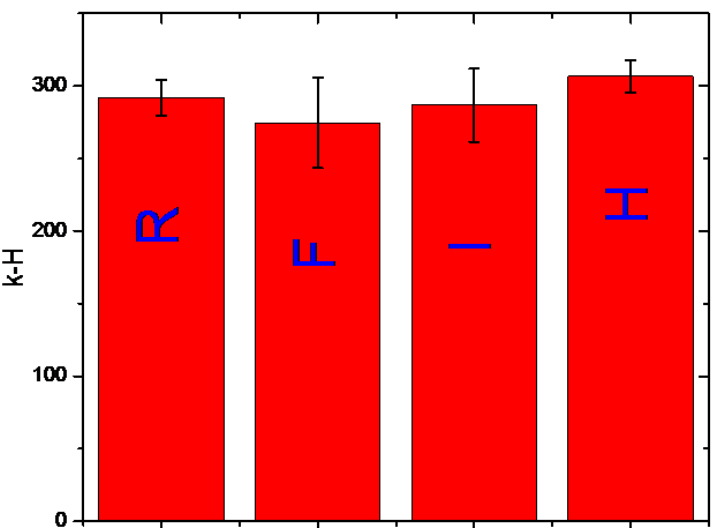

b.

Fig. 4. Comparison of a. strain hardening exponent $(n-H)$ and b. stress index $(k-H)$ determined using Hollomon's equation.

The strain hardening exponent $(\mathrm{n}-\mathrm{H})$ determined by Hollomon's equation does not vary significantly but it shows a large spread especially for the processed samples, same observations are to be applied to the stress index (k-H). As described in equation (1) the yield strength of the material is not accounted for, thus using this method to study the strain hardening exponent does not yield good results.

In Ludwik's equation (2) the yield strength is accounted and the results describe in a more accurate manner the material behavior, a comparison of the predicted values of the strain hardening exponent is shown in Figure 5.a. and $b$.

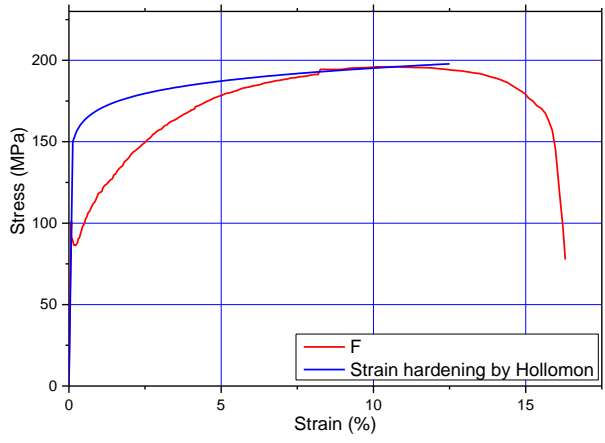

a.

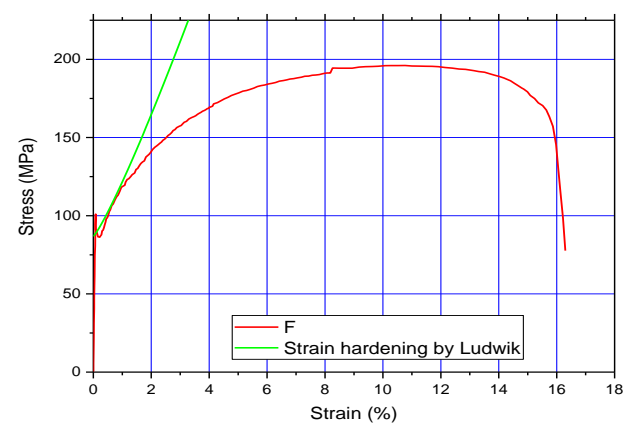

b.

Fig. 5. Graphical representation of a. Hollomon's and b. Ludwik's equations adapted to engineering stress - strain curves for a heated sample $(\mathrm{F})$.

Even when Ludwik's equation is employed, in Figure 5.b it can be seen that strain hardening could be studied by dividing the curve on intervals and computing for each interval both parameters. In this study the strain hardening when plastic deformation is setting was considered more relevant from a mechanical perspective [9].

In Figure 6.a the variation of the strain hardening exponent (n-L) is shown, suggesting that the materials repaired by heating ( $\mathrm{F}$ and $\mathrm{I})$ work harden in a greater extent than the reference $(\mathrm{R})$ while the cold worked materials $(\mathrm{H})$ strain hardens least. This behavior is as expected and the data spread for heated samples can be explained that heating was performed by hand and in various amounts, depending on the amount of damage.

The stress index (k-L) shows a similar variation (seen in Figure 6.b.) as the strain hardening exponent suggesting that heated materials would require higher strengths for the onset of plastic deformation and strain hardening.

Again, large data spread was observed, given the repair procedures employed. 


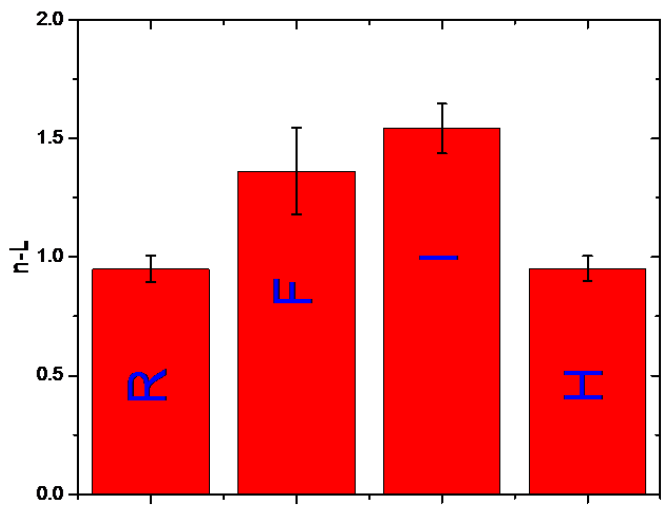

a.

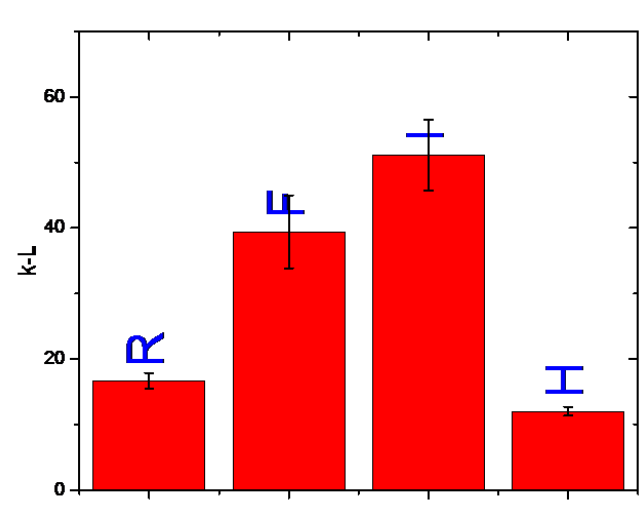

b.

Fig. 6. Comparison of a. strain hardening exponent (n-L) and b. stress index (k-L) determined using Ludwik's equation.

\subsubsection{Tensile behavior from microstructure point o view}

Heating the steel well above critical temperatures causes grain growth. Both methods, flame and induction heating, are capable of generating enough energy to heat the material well above its critical temperature. Temperature control, in practice, is mainly performed by heating color which is subjective and hard to appreciate in various lighting conditions, thus overheating occurs frequently.

In an attempt to relate the mechanical properties, more precisely the yield strength, we used the Hall-Petch relationship. Using equation (3) the yield stress can be related with the grain size of the steel [10, 11].

$$
\sigma_{y}=\sigma_{0}+\frac{k_{y}}{\sqrt{d}}
$$

In equation (3) $\sigma_{y}$ represents the yield stress, $\sigma_{0}$ is a materials constant representing the stress for dislocation movement, $k_{y}$ is the strengthening coefficient, material specific, and $d$ is the average grain diameter. For mild steels values for $\sigma_{0}=70 \mathrm{MPa}$ and $k_{y}=0.74 \mathrm{MPa} \sqrt{\mathrm{m}}$ can be found in literature [12 - 14].

In Figure 7 a dependence of the yield stress on the average grain diameter is shown.

According to the Hall-Petch equation a material can be made infinitely strong as its grain become infinitely strong, and, in reverse, as the grain size increases, the yield stress of the material decreases accordingly.

We solved equation (3) for the average grain diameter using as input the experimentally determined yield strength (YS), the results are shown in Table 3 and the grain size number G was associated according to ASTM E112.

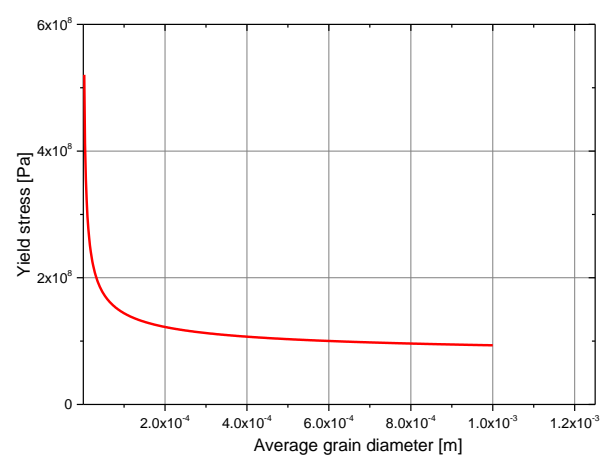

Fig. 7. Graphical representation of the Hall - Petch relation showing Yield stress - grain size relationship for mild steel. 
Table 3. Computed average grain diameter and its association with ASTM E112 grain size number.

\begin{tabular}{|c|c|c|c|}
\hline Sample & $\begin{array}{c}\text { Experimental Yield } \\
\text { Strength YS [MPa] }\end{array}$ & $\begin{array}{c}\text { Computed average grain } \\
\text { diameter d [mm] }\end{array}$ & Grain size number G \\
\hline $\mathrm{R}$ & 169.5 & 0.05556 & 5.5 \\
\hline $\mathrm{F}$ & 108 & 0.37868 & 0 \\
\hline $\mathrm{I}$ & 112.75 & 0.2999 & 0.5 \\
\hline $\mathrm{H}$ & 182 & 0.04359 & 6.0 \\
\hline
\end{tabular}

As the grain size increases, the yield strength decreases, as presented in Figure 8.

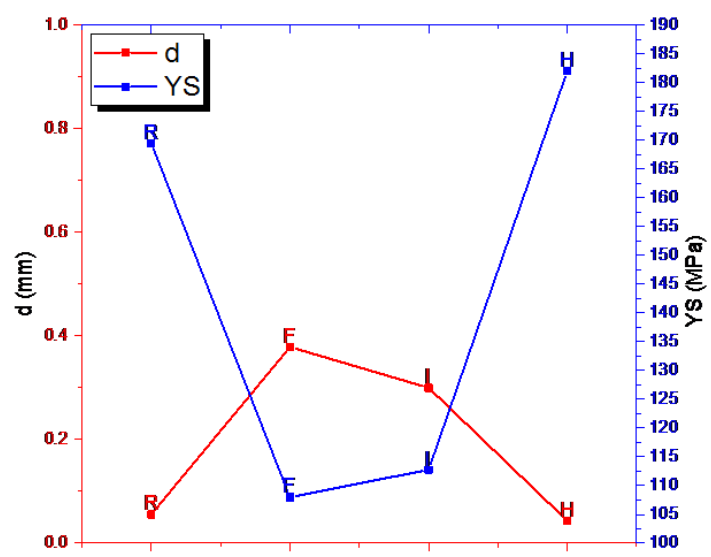

Fig. 8. Correlation between experimental yield strength (YS) and computed average grain diameter (d).

Since repairs are performed by local heating specific regions would have large grains with low ductility and tensile strength. These regions behave different when compared with the rest of the material, being more strained and thus are prone to failure.

As an ensemble the material behaves as a composite being more difficult to assess its mechanical properties and behavior.

\subsection{Inhomogeneous materials behavior in an impact}

To show the importance of the homogeneity of the materials structure a simple simulation was devised with a structure comprised of four panels with various mechanical properties. This panel was loaded in compression and the stress and strain distribution observed.

The stress distribution presented in Figure 9.a. appears to be uniform throughout the whole assembly, while the strains, observed in Figure 9.b. appear highest in the components with lower mechanical characteristics [15].

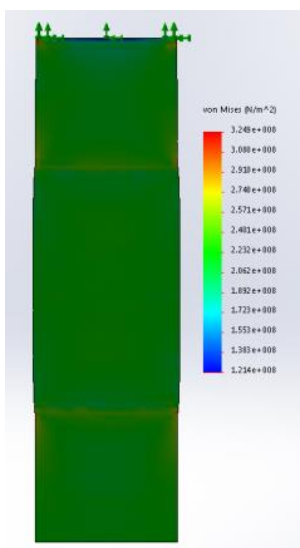

a.

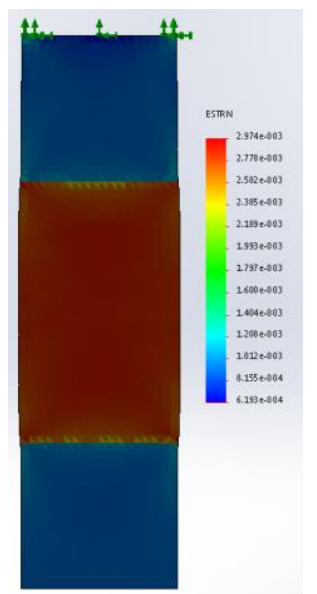

b.

Fig. 9. Simulation results showing a. von Misses stresses and b. strain distribution in the assembly. 


\section{CONCLUSION}

This study illustrates the importance of the processing history of the material on its mechanical properties.

Microstructure variation in a component changes its mechanical behavior when stressed thus invalidating the assumptions of homogeneity and isotropy made when strength computations are performed.

Steels are still widely used in automotive industry and their mechanical behavior must be understood and associated with their microstructure which, in turn, needs to be associated with the processing route.

Repair procedures of the structural components of a car should be well documented and controlled, and, if possible, avoided. It is strongly recommended to perform repairs by cold working.

Various microstructures in a material creates anisotropy and the mechanical behavior is more similar to a composite.

\section{REFERENCES}

[1] Heisler, H.B., Advanced vehicle technology Great Britain, Butterwoth - Heinemann, second edition, vol. 8, 2002 , p. $1-24$.

[2] Garret, T.K., Newton, K., Steeds, W., The motor vehicle, Butterwoth - Heinemann, Great Britain, 13th edition, 2001, p. $915-983$.

[3] Mo, D.F., He, G.Q., Hu, Z.F., Liu, X.S., Zhang, W.H., Effect of microstructures on strain hardening exponent prediction of cast aluminum alloy. Acta Metall Sin, vol. 46, 2010 184-188.

[4] Song, Y.Q., Hai, J.T., Guan, Z.P., Mechanical analysis of the strain-hardening exponent under tensile deformation, Sci China Ser E, vol. 44, 2002, p. 647-653.

[5] Hortigon, B., Gallardo, J.M., Nieto-Garcia, E.J., Lopez, J.A., Strain hardening exponent and strain at maximum stress: Steel rebar case, Construction Build Mater, vol. 196, 2019, p. 175-184.

[6] Zhang, Z.P., Sun, Q., Li, C.W., Zhao, W.Z., Theoretical calculation of the strain-hardening exponent and the strength coefficient of metallic materials, Journals of Materials Engineering and Performance, vol. 15, 2002, p. 19-22.

[7] Schwartz, M., Ciocoiu, R., Gheorghe, D., Ciuca, I., Failures of AISI H21 die in copper hot extrusion. Materials at High Temperatures, vol. 31, 2004, p. 95-101.

[8] Samuel, K.G., Limitations of Hollomon and Ludwigson stress-strain relations in assessing the strain hardening parameters, Journal of Physics D: Applied Physics, vol. 39, 2006, p. 203-212.

[9] Matyunin, V.M., Interrelationship of the strain-hardening exponent in tension and indentation, Industrial Lab+, vol. 52, 1986, p. 871-872.

[10] Xu, W.W., Davila, L.P., Tensile nanomechanics and the Hall-Petch effect in nanocrystalline aluminium, Materials Science and Engineering a-structural Materials Properties Microstructure and processing, vol. 710, 2018, p. 413-418.

[11] Li, C.L.; Mei, Q.S., Li, J.Y., Chen, F., Ma, Y., Mei, X.M., Hall-Petch relations and strengthening of Al-ZnO composites in view of grain size relative to interparticle spacing, Scripta Materialia, vol. 153, 2018, p. 27-30.

[12] Bergstrom, Y., Hallen, H., Hall-petch relationships of iron and steel, Metal Science, vol. 17, 1983, p. 341347.

[13] Mintz, B., Importance of Ky (Hall-Petch slope) in determining strength of steels, Metal Technology, vol. 11, 1984, p. 265-272.

[14] Choi, H.C., Park, K.T., The effect of carbon content on the Hall-Petch parameter in the cold drawn hypereutectoid steels, Scripta Materialia, vol. 34, 1996, p. 857-862.

[15] Takimoto, A., Fujiwara, M., The variation of the strain-hardening exponent due to grain-size distributions in engineering metallic sheet materials, JSME International Journal, vol. 30, 1987, p. 921-928. 